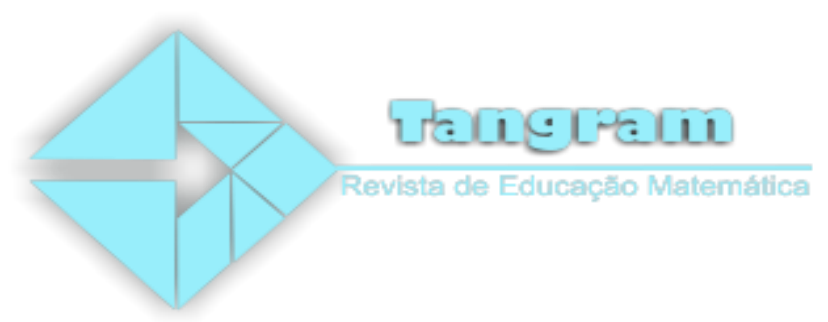

\title{
Uso de tecnologias nas aulas de matemática: pesquisa com professores da cidade de Dourados (MS)
}

\section{Use of technologies in Mathematics classes: research with teachers from the city of Dourados (MS)}

\author{
Keli Cristina Conti ${ }^{1}$ \\ Dênis Rodrigues da Silva ${ }^{2}$
}

\begin{abstract}
Resumo
Esse trabalho apresenta uma releitura um trabalho de conclusão de curso (2017), em que realizamos uma pesquisa do tipo levantamento ou survey, com professores de Matemática atuantes em escolas públicas na cidade de Dourados (MS). Fizeram parte da pesquisa 29 professores, participando por meio de questionários impressos e eletrônicos. Objetivando saber se os professores de Matemática da cidade de Dourados, Mato Grosso do Sul, utilizavam tecnologias em suas aulas, buscou-se neste trabalho, responder a seguinte questão: Os professores de Matemática da cidade de Dourados, estado de Mato Grosso do Sul, utilizam tecnologias em suas aulas? Através dos resultados encontrados pudemos concluir que tais professores utilizam pouco as tecnologias nas aulas de Matemática, frente à grande frequência de utilização fora dela e devido a fatores diversos, tem sido desafiante para a maioria desses professores aumentar essa frequência.
\end{abstract}

Palavras-chave: Educação Matemática; Matemática; Tecnologias.

\section{Abstract:}

This work presents a review of a course completion (2017), in which we conducted a research survey or survey, with teachers of mathematics acting in public schools in the city of Dourados (MS). Twenty-nine teachers participated in the study, participating through paper and electronic questionnaires. In order to know if the Mathematics teachers of the city of Dourados, Mato Grosso do Sul, used technologies in their classes, we sought to answer the following question: Mathematics teachers of the city of Dourados, state of Mato Grosso do Sul, do they use technologies in their classrooms? Through the results found we could

\footnotetext{
${ }^{1}$ Professora Adjunta do Departamento de Métodos e Técnicas Educacionais (DMTE) da Faculdade de Educação da Universidade Federal de Minas Gerais (UFMG). Orientadora do Trabalho de Conclusão de Curso. E-mail: keli.conti@gmail.com

${ }^{2}$ Concluinte da Licenciatura em Matemática da Universidade Federal da Grande Dourados (UFGD). E-mail: denis.matufgd@gmail.com
}

Tangram - Revista de Educação Matemática, Dourados - MS - v.1 n. 1, pp. 54 - 74 (2018) 
conclude that such teachers use little technology in mathematics classes, due to the great frequency of use outside of it and due to different factors, it has been challenging for most of these teachers to increase this frequency.

Keywords: Mathematics Education; Mathematics; Technologies.

\section{Introdução}

É possível perceber, por tudo que nos cerca, que houve grandes evoluções em nossa sociedade ao longo das últimas décadas no que diz respeito às tecnologias. Atualmente em meio à era digital, as tecnologias da informação e comunicação, vêm modificando cada vez mais a dinâmica de vida das pessoas e abrindo espaço para que se tornem presentes e indispensáveis em diversas funções cotidianas, seja na parte pessoal ou profissional.

Hoje é possível ler um livro, por exemplo, fisicamente (impresso) ou digital por meio dos computadores, tablets e smartphones. Ao longo dos anos as tecnologias evoluíram (e ainda evoluem), e é cada vez mais provável que a cada nova descoberta a anterior se torne antiquada e ultrapassada, mas será que as pessoas acompanharam esta evolução?

E a escola nesse contexto? Analisando alguns parâmetros do desenvolvimento da sociedade podemos notar que devemos ter na tecnologia uma grande e importante aliada para que cada vez mais as pessoas aprendam de forma diferenciada e atrativa afastando-se um pouco do tradicional quadro e giz.

E para delimitar nossas discussões, e a Matemática nesse contexto de tecnologia da informação e comunicação (TIC)?

Com essas indagações e com o objetivo de saber se os professores de Matemática da cidade de Dourados (MS), utilizam tecnologias em suas aulas, buscou-se, num trabalho de conclusão de curso (TCC), responder a seguinte questão: Os professores de Matemática da cidade de Dourados, estado de Mato Grosso do Sul, utilizam tecnologias em suas aulas?

Nesse contexto, trazemos aqui, uma releitura de um trabalho de conclusão de curso (SILVA, 2017), buscando apresentar, por meio de pesquisa bibliográfica, elementos da tecnologia, seu uso e mais especificamente o uso de tecnologia nas aulas de Matemática e posteriormente trecho da pesquisa aplicada a 29 professores de Matemática da cidade de Dourados (MS), cujo foco foi o uso de tecnologia nas aulas de Matemática. Depois disso apresentamos um pouco sobre a relação dos professores com as tecnologias, as mais utilizadas nas aulas, bem como sua frequência e os softwares conhecidos e usados pelos

Tangram - Revista de Educação Matemática, Dourados - MS - v.1 n. 1, pp. 54 - 74 (2018) 
professores participantes da pesquisa. Por fim, apresentamos as análises dos resultados encontrados e algumas considerações acerca do desenvolvimento do trabalho.

\section{Tecnologia}

Ao discutir conceitos de tecnologia devemos levar em consideração alguns aspectos da história e evolução da tecnologia. Antigamente, na idade da pedra os humanos utilizavam alguns recursos da natureza como pedras e troncos de árvores na construção de ferramentas para sobrevivência, com a descoberta do cobre e do ouro substituía - se já os artefatos de pedra pelos de metal e assim sucessivamente.

De forma geral, as tecnologias são intrinsecamente relacionadas com a história da humanidade, e graças e engenhosidade humana foram dadas origens as mais diversas tecnologias, como a tecnologia educacional, por exemplo.

Ao falarmos em tecnologia o que vem em imediato à mente das pessoas são recursos informáticos e alguns eletrônicos utilizados em filmes em ficção científica, por exemplo, mas de acordo com Filho, Maia, Castro, Barreto e Freire (2016) "tecnologia pode ser entendida como um conjunto de conhecimentos ou instrumentos aplicados na execução de uma tarefa ou resolução de problemas. Assim, tanto a nossa linguagem, o lápis, o papel, o computador são tecnologias" (p. 13).

Nesse sentido Kenski (2003) afirma que "estamos vivendo um novo momento tecnológico" (p. 2). Com isso, as possibilidades de comunicação e de informação tem se ampliado. Equipamentos como os telefones, smartphones, televisão, computadores, tablets tem alterado nossa forma de viver e interagir na atualidade. Kenski (2003) afirma também que "desde o início da civilização, o predomínio de um determinado tipo de tecnologia transforma o comportamento pessoal e social de todo o grupo" (p. 2).

Carneiro (2008) ressalta outros exemplos das transformações tecnológicas atuais possibilitadas pelas invenções dos microprocessadores e computadores (p. 29):

\footnotetext{
A evolução da microeletrônica tornou possível a criação, primeiro dos transistores, circuitos integrados, e depois dos microprocessadores, que deram origem aos computadores. Não se pode deixar de acrescentar que com o desenvolvimento das telecomunicações tivemos o advento da Internet e dos telefones celulares. $\mathrm{O}$ computador modificou a vida das pessoas. Essas máquinas facilitam a realização de muitas tarefas e também possibilitam outras que não poderiam ser realizadas sem elas. As câmeras fotográficas digitais, os MP3 players, os telefones celulares já fazem parte da vida de milhões de pessoas em todo o mundo. Mais
}

Tangram - Revista de Educação Matemática, Dourados - MS - v.1 n. 1, pp. 54 - 74 (2018) 
recentemente, tem-se a entrada do Brasil no mundo da TV digital como outro exemplo das transformações tecnológicas atuais.

Nesse cenário de transformações, com o surgimento da internet, de acordo com Carneiro (2008), tivemos mudanças em relação ao tempo e ao espaço que possibilitou a diminuição de distâncias. Nesse sentido exemplifica (p. 30)

Comunicamo-nos com pessoas do outro lado do mundo a qualquer hora como se estivéssemos falando com um vizinho ao telefone; temos acesso a notícias recentes em questão de minutos; os usuários dos sites de relacionamento e dos softwares de comunicação instantânea crescem exponencialmente a cada dia; compramos passagens aéreas, livros, entradas de cinema e uma grande variedade de coisas sem sair de casa; acessamos sites de universidades e bibliotecas europeias, visualizando obras disponibilizadas online em questão de segundos e podemos visitar virtualmente lugares que nunca visitaremos de fato.

Além disso, há inúmeras situações em que a tecnologia está presente: na indústria (automação), no campo (máquinas que fazem a colheita), na saúde (código genético), entre outras.

A educação vem sendo afetada por diversas modificações do cenário tecnológico atual, sendo uma delas a ampliação de fontes e formas de acesso a informações às quais os estudantes podem ter acesso e a escola passaria a ser mais uma delas.

Acreditamos que a educação não ficou isolada, mas também foi afetada por esse contexto de evolução. Nesse sentido, nos indagamos: e a escola nesse contexto? Passaremos então a refletir sobre o uso das tecnologias nas escolas.

\section{Tecnologias e seu uso nas escolas}

Em constante evolução as tecnologias na educação presentes ao longo da história da sociedade ganharam terminologias importantes até chegarmos ao conceito de Tecnologias de Informação e Comunicação (TIC).

O termo Tecnologia Educativa (TE) que valoriza a instrução, tem sua raiz na tradição anglo-saxônica ${ }^{3}$, é um domínio da educação que teve origens nos anos 40 e foi desenvolvido

\footnotetext{
${ }^{3}$ Refere-se aos países do continente americano que tem como principal idioma o inglês e que também possuam laços históricos, étnicos, linguísticos e culturais com o Reino Unido. Apesar de a denominação "anglosaxônica" ser frequentemente aplicada apenas aos países desenvolvidos da América do Norte (Canadá e Estados Unidos da América), também integram o grupo a Guiana (situada na América do Sul) e Belize (América Central).
}

Tangram - Revista de Educação Matemática, Dourados - MS - v.1 n. 1, pp. 54 - 74 (2018) 
por Skinner ${ }^{4}$ na década seguinte com o ensino programado, sendo que esse termo não limita aos recursos técnicos usados no ensino, mas todos os processos de concepção, desenvolvimento e avaliação da aprendizagem. De acordo com Miranda (2007) considerando o domínio da Tecnologia Educativa são englobados três subdomínios que influenciam o aluno na aprendizagem e são: “(1) as funções de gestão educacional, (2) as funções de desenvolvimento educacional e (3) recursos de aprendizagem”. (p. 42-43). O uso educativo do computador e da internet é considerado um subdomínio da TE.

O termo Tecnologias Aplicadas à Educação (TAE), é considerado sinônimo do anterior, e trata de aplicações da tecnologia aos processos envolvidos no funcionamento da educação. Quem trabalha no domínio da TE não se interessa apenas por avanços técnicos e recursos, mas também por processos que determinam e melhoram a aprendizagem, sendo que esses processos podem integrar recursos como computador e internet, por exemplo.

Miranda (2007) a respeito do termo Tecnologias da Informação e Comunicação enfatiza: "refere se à conjugação da tecnologia das telecomunicações e tem na internet e mais particularmente na World Wide Web (WWW) a sua mais forte expressão" (p. 43). Quando utilizadas para fins educativos no intuito de promover a aprendizagem dos alunos e desenvolver seus ambientes as TIC podem ser consideradas como um subdomínio da Tecnologia Educativa.

O desconhecimento das tecnologias pode trazer resistências quanto ao seu uso em sala de aula, por simplesmente desconhecerem ferramentas para sua utilização ou se sentirem despreparados para utiliza-las, pois, somente implantar computadores nas aulas não vai mudar a prática docente e apenas utilizá-lo como uma ferramenta mecânica, não gera, muitas vezes, interesse. Nesse contexto, é necessário que os estudantes deem sentido de descoberta por meio da investigação para que seja algo inovador e prazeroso.

A instalação de equipamentos nas escolas, tais como computadores, televisores, DVD's entre outros e acesso à internet, não é sinônimo de ensino de qualidade, podendo camuflar práticas convencionais adotadas pelos professores. Um entre outros argumentos para a inserção das Tecnologias da Informação e Comunicação (TIC) na educação é a utilização de recursos tecnológicos na escola para a preparação dos estudantes para o mercado de trabalho o que sem dúvidas na sociedade contemporânea é de extrema

\footnotetext{
${ }^{4}$ Burrhus Frederic Skinner nasceu em Susquehanna, no estado norteamericano da Pensilvânia, em 1904. Foi um estudante rebelde, cujos interesses, na adolescência, eram a poesia e a filosofia.

Tangram - Revista de Educação Matemática, Dourados - MS - v.1 n. 1, pp. 54 - 74 (2018)
} 
importância, uma vez que cada vez mais têm sido comum a substituição de mãos de obra por computadores e assim devem estar instrumentalizados, habilitados e preparados para essas funções, porém essa não deve ser a principal razão.

A utilização das diversas tecnologias existentes deve ocorrer em todas as disciplinas do currículo escolar, objetivando modificar o processo e ensino e aprendizagem e contribuição na dinâmica da aula tornando esse processo aliado da prática do professor em sala de aula, para tanto é necessário que o professor considere alguns aspectos como: o processo tecnológico (potencialidades encontradas na tecnologia), o processo pedagógico (maneira que as atividades são desenvolvidas e seus objetivos) e o processo formativo (desenvolvimento da atividade e inclusão e redefinição dos procedimentos de uso). Esses processos devem estar intimamente interligados e funcionando em sintonia, pois se um desses ocorrer de forma assíncrona à potencialidade do meio tecnológico poderá ocorrer de forma insatisfatória o desenvolvimento da atividade proposta pelo professor.

Ainda sim, considerando tais perspectivas, muitos professores atualmente utilizam de forma tímida tecnologias em sala de aula. Esse fator pode ser justificado pelo fato que ao utilizar recursos tecnológicos em sala de aula o professor deixe a chamada "zona de conforto" e trafegue em direção a chamada "zona de risco", sendo que a primeira é caracterizada basicamente por quase tudo ser conhecido, controlável e previsível e a segunda que surge de dúvidas, problemas técnicos e diversidade de caminhos encontrados pelos estudantes quando trabalham em um computador.

Ainda sobre a zona de risco, Carneiro e Passos (2014) trazem que:

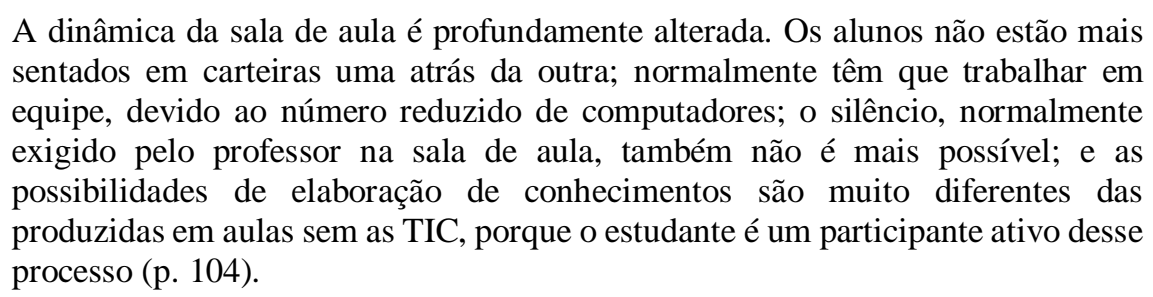

A atmosfera na sala de aula a partir de então, e a relação entre professor e aluno transforma-se, de uma dimensão comum em sala de aula em que o professor é autoridade e detentor do conhecimento para uma em que o mesmo não domina certo conhecimento referente às tecnologias, o aluno passa a ter mais autonomia e autoridade na aula.

A forma com que o professor utilizar um recurso tecnológico em sala deve ter bem definido, seus objetivos e conhecimentos técnicos profundos acerca dos limites e 
potencialidade acerca do software ou recurso trabalhado, um bom planejamento já visando prever dúvidas e possíveis questionamentos que os estudantes possam fazer.

Entretanto uma delicada, porém, importante questão a ser tocada é: Qual a política de implementação do uso de tecnologias adotada nas escolas?

Embora não seja nosso foco a discussão de política públicas de implementação, de acordo com Bittar (2010), muitas escolas têm sido equipadas com laboratórios de informática (LI), porém há uma divisão nas ações de como têm sido utilizadas as tecnologias com os estudantes, a saber: (1) criação de uma disciplina de informática educativa desenvolvida por um professor de laboratório e (2) aulas realizadas com o professor de uma disciplina específica, a primeira trata de assuntos gerais que podem ou não ser interligados (interdisciplinaridade) e a segunda são estudados assuntos e realizadas tarefas específicas a área e conteúdo estudado.

E ainda de acordo com a autora acima, algumas escolas desenvolvem ambas as ações sendo que na maioria das vezes o professor de informática basicamente auxilia o professor da disciplina na escolha do software ou recurso e na preparação das atividades, as escolas que não tem curso de informática têm um responsável de laboratório que trabalha junto com os professores, porém nitidamente pode se notar que na maioria dos casos ele dificilmente terá conhecimento das características particulares da disciplina em questão.

De acordo com Paz (2014): "as escolas do estado de Mato Grosso do Sul contam hoje com a Sala de Tecnologia Educacional (STE), que estão providas de equipamentos de informática que professores podem utilizar como recurso extra para ministrar aulas" (p. 21). Normalmente há um ou mais responsáveis exclusivamente por este espaço na escola.

É importantíssimo distinguir integração e inserção da tecnologia da educação. O uso do computador pode e deve ser avaliado e usado como qualquer outro, tal como o giz, por exemplo. Integrar um software ou recurso, à prática pedagógica, significa que ele poderá ser usado em diversos momentos do ensino e sempre que necessário, for contribuindo substancialmente no processo de aprendizagem do estudante. Inserir tecnologia na educação é o que tem sido feito na maioria das escolas e de acordo com Bittar (2010):

Coloca-se o computador nas escolas, os professores usam, mas sem que isso provoque uma aprendizagem diferente do que se fazia antes e, mais do que isso, o computador fica sendo um instrumento estranho (alheio) à prática pedagógica, sendo usado em situações incomuns, extraclasses, que não serão avaliadas (p. 220).

Tangram - Revista de Educação Matemática, Dourados - MS - v.1 n. 1, pp. 54 - 74 (2018) 
E ainda, Bittar (2010), também aponta que: “Integrar um novo instrumento em sala de aula implica mudanças pedagógicas, mudanças do ponto de vista da visão de ensino, que devem ser estudadas e consideradas pelos professores" (p. 220).

Pensando na integração das Tecnologias de Informação e Comunicação (TIC), e vendo-as como ferramentas que auxiliam no processo de ensino-aprendizagem, é que passamos a discutir a utilização das mesmas, nas aulas de Matemática.

\section{O uso de tecnologias nas aulas de Matemática}

Com o objetivo de aprofundarmos as reflexões sobre o uso das tecnologias digitais nas escolas, propomos uma discussão sobre seu uso nas aulas de Matemática, como forma também de discutirmos suas potencialidades e limitações para o ensino aprendizagem nessa disciplina.

De acordo com Borba, Silva e Gadanidis (2014), há uma perspectiva estruturada em quatro fases, quando se pensa em tecnologias na Educação Matemática no Brasil. Ainda segundo os autores, as fases não são disjuntas, havendo muitas similaridades e particularidades entre elas. Passamos a caracterizar as fases, baseando-nos em Borba, Silva e Gadanidis (2014):

\section{1. ${ }^{\mathrm{a}}$ Fase:}

Já se discutia, na década de 1980, em Educação Matemática, o uso de computadores, calculadoras simples e científicas. De acordo com os autores citados, usava-se a expressão "tecnologias informáticas (TI)" (p. 18) quando as pessoas queriam se referir ao computador ou software. Os autores também apresentam que "a primeira fase é caracterizada fundamentalmente pelo uso do software $\mathrm{LOGO}^{5}$, que teve início por volta de 1985" (p. 18), e a principal perspectiva teórica sobre o uso pedagógico do LOGO é o Construcionismo ${ }^{6}$, que enfatiza relações entre linguagem de programação e pensamento matemático.

\footnotetext{
${ }^{5}$ A linguagem de programação LOGO foi desenvolvida em meados dos anos 60 no Massachusetts Instituto de Tecnologia, nos EUA, por Seymour Papert e colaboradores, com o objetivo de utilizá-la para fins educacionais. ${ }^{6} \mathrm{O}$ Construcionismo é uma teoria proposta por Seymour Papert, matemático e um dos pioneiros no campo da Inteligência Artificial. Reconhecido internacionalmente como o primeiro a pesquisar de que modo os computadores poderiam contribuir com o processo de aprendizado das crianças.
}

Tangram - Revista de Educação Matemática, Dourados - MS - v.1 n. 1, pp. 54 - 74 (2018) 
Borba, Silva e Gadanidis (2014), informam que "cada comando do LOGO determina um procedimento a ser executado por uma tartaruga (virtual). Os movimentos da tartaruga como passos e giros, possibilitam a construção de objetos geométricos como segmentos de reta e ângulos (p. 20), (Figura 1).

Figura 1: Interface do software SuperLogo

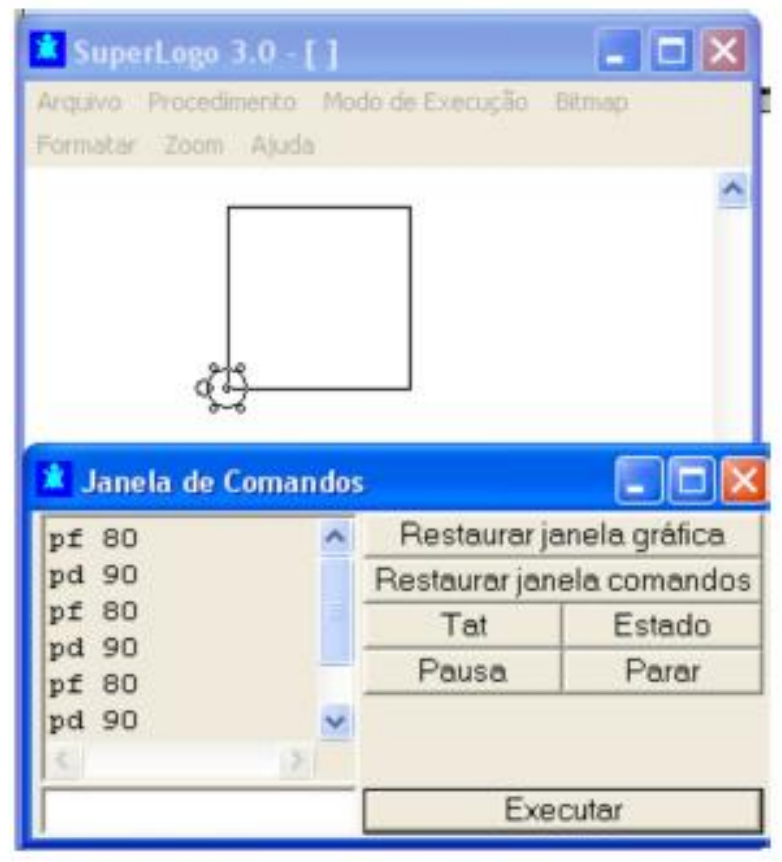

Fonte: Bittar, 2010, p. 229.

Nesse período também surge a "perspectiva de que as escolas poderiam ou deveriam ter laboratórios de informática" (p. 20). Atribui-se nessa fase, as tecnologias, um papel de “catalisador para a mudança pedagógica" (p. 21), complementando que "A ideia era que as possibilidades oferecidas pelos computadores permitiriam abordagens inovadoras para a educação, ajudando a formar cidadãos reflexivos que poderiam explorar as tecnologias em outras situações e na construção de conhecimentos pessoais" (p. 21).

Podemos também citar pesquisadores que desempenharam papéis fundamentais na Educação Matemática, quando se fala em transformação das práticas pedagógicas e didáticas com o uso de TI: José Armando Valente, Janete Frant, Lulu Healy e Léa Fagundes.

\section{2. ${ }^{\mathrm{a}}$ Fase}

Com o avanço da acessibilidade e a popularização dos computadores pessoais (PCs) na primeira metade dos anos 90 houve grandes variedades de perspectivas sobre o papel dos Tangram - Revista de Educação Matemática, Dourados - MS - v.1 n. 1, pp. 54 - 74 (2018) 
computadores pessoais na vida pessoal e profissional das pessoas, mas ainda haviam muitas pessoas que por diversas razões entre elas, falta de oportunidade, nunca haviam utilizado um computador pessoal. Partindo da perspectiva que algumas pessoas não visualizavam novos rumos que o uso dos computadores pessoais poderia trazer ao desenvolvimento da humanidade e outros perceberem transformações cognitivas, sociais e culturais que ocorreriam com uso de TI diversos softwares educacionais foram elaborados por empresas, governos e pesquisadores.

A partir desse momento os professores por meio de formações continuadas puderam ter alternativas e suporte para a utilização da TI em suas aulas, sendo assim necessário que tais professores percorressem o caminho da zona de conforto para a zona de risco.

Borba, Silva e Gadanidis (2014) colocam com destaque os softwares voltados à representações de funções Winplot, Fun, Graphmathica e Geometria Dinâmica (GD) CabriGeomètre, Geometricks devido a sua natureza dinâmica, experimental e visual.

$\mathrm{Na}$ geometria dinâmica, o dinamismo era atrelado ao fato da manipulação, visualização e construção de objetos geométricos, traçando caminhos de investigação, e já introduzindo uma distinção na relação entre construção e desenho que não faziam sentido quando construído tais objetos geométricos em papel.

Ainda de acordo com Borba, Silva e Gadanidis (2014), temos que: "Parte fundamental do nosso trabalho é buscar novos tipos de problemas e diversificados tipos de soluções com o surgimento de uma nova tecnologia. Muitas vezes um problema que poderia ser didático com uma tecnologia não é com outra” (p. 24).

Um problema clássico dessa fase apontado por Borba, Silva e Gadanidis (2014) é o da construção de um quadrado com o software CabriGeomètre (Figura 2) ou Geometricks para introduzir a noção de construção em geometria dinâmica.

Figura 2: Interface do software CabriGeomètre ${ }^{7}$

\footnotetext{
${ }^{7}$ Cabri-Geomètre é um software de construção em geometria desenvolvido pelo Institut d'Informatique et de Mathematiques Appliquees em Grenoble, França - IMAG. É um software de construção que nos oferece "régua e compasso eletrônicos", sendo a interface de menus de construção em linguagem clássica da Geometria.

Tangram - Revista de Educação Matemática, Dourados - MS - v.1 n. 1, pp. 54 - 74 (2018)
} 


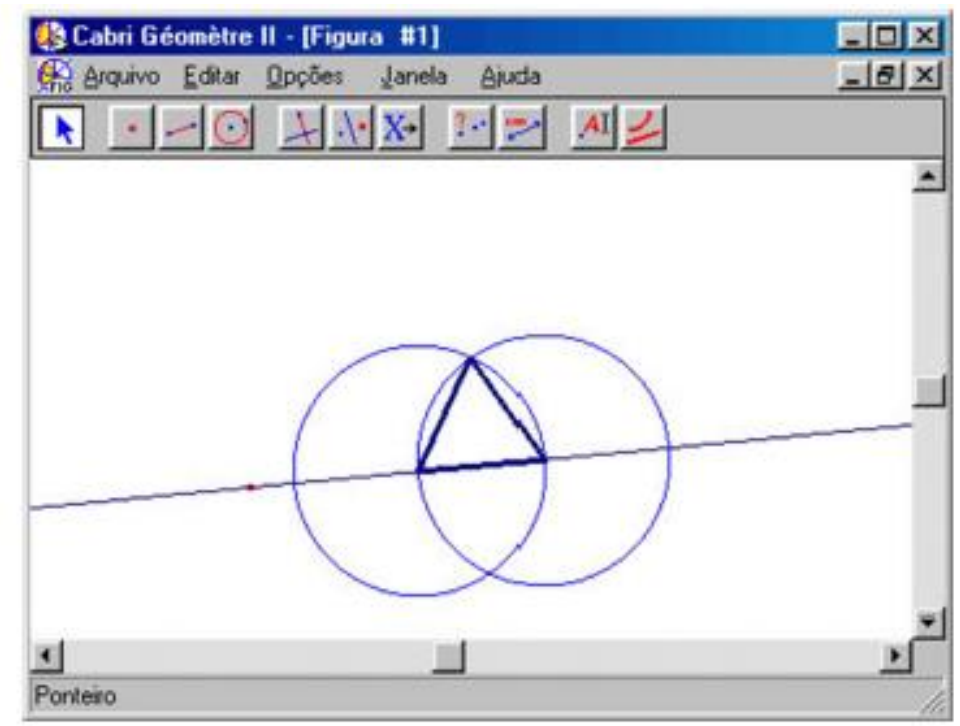

Fonte: http://www2.mat.ufrgs.br/edumatec/softwares/interfaces/cabri.jpg

Na parte dos softwares gráficos a investigação também é presente, e a possibilidade de gráficos de funções serem gerados por calculadoras gráficas e softwares como Winplot, por exemplo, fez com que novos problemas pudessem ser discutidos em diversos níveis de ensino, como problema de derivadas, por exemplo.

\section{3. ${ }^{\mathrm{a}}$ Fase}

Por volta de 1999 temos o início dessa fase marcada pelo advento da internet. A partir de então, a internet começa a ser utilizada como meio de comunicação e fonte de informações entre estudantes e professores na realização de cursos à distância na formação de professores. Nesse momento além do termo "tecnologias informáticas" (TI), surgem e consolidam se mais dois, a saber, "tecnologias da informação" e "tecnologias da informação e comunicação" (TIC).

Um software de grande destaque nessa fase foi o Winplot (Figura 3), oferecendo meios para a exploração de soluções dos problemas de forma algébrica e gráfica, como por exemplo, a resolução da equação exponencial $2^{\mathrm{x}}=5$.

Figura 3: Interface do software Winplot ${ }^{8}$

\footnotetext{
${ }^{8}$ Winplot é um software que permite que se construam gráficos a partir de funções elementares. Possibilita que se construam gráficos em duas e três dimensões e ainda que se trabalhe com operações de funções.

Tangram - Revista de Educação Matemática, Dourados - MS - v.1 n. 1, pp. 54 - 74 (2018)
} 


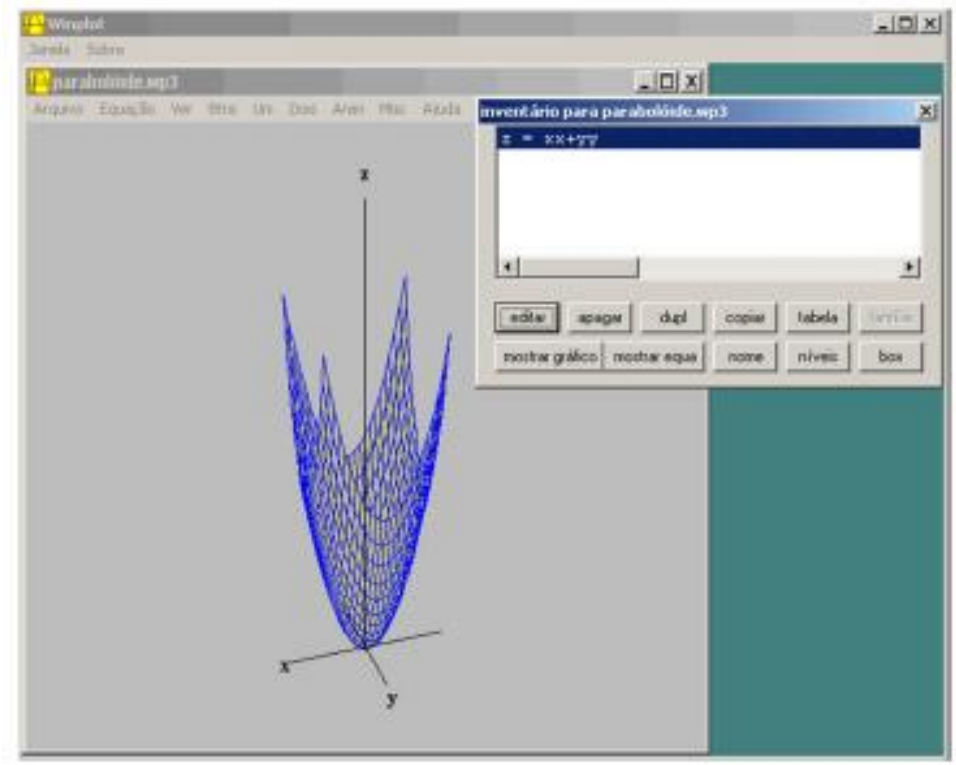

Fonte: http://www2.mat.ufrgs.br/edumatec/softwares/interfaces/winplot.jpg

Borba, Silva e Gadanidis (2014) trazem que "essa fase encontra se em franco desenvolvimento e vem transformando softwares da segunda fase e ao mesmo tempo influenciada por novas possibilidades da quarta fase" (p. 35).

\section{4. ${ }^{\mathrm{a}}$ Fase}

Atualmente vivenciamos esta fase, iniciada em meados de 2004 com relação ao uso de tecnologias em Educação Matemática e advento da internet rápida, dos diversos recursos que possui e que transformaram e transformam a forma de comunicação entre pessoas e que tem sido cada vez mais aprimorada.

Segundo Borba, Silva e Gadanidis (2014), nesta fase utiliza-se o termo "tecnologias digitais" (TD), caracterizada por diversos aspectos, tais como: Geogebra, Multimodalidade, Novos designs e interatividade, Tecnologias móveis ou portáteis, Performance e Performance matemática digital.

Conforme Borba, Silva e Gadanidis (2014), com o surgimento de uma "nova fase" não há a exclusão, substituição ou extinção da fase anterior, mas certa sobreposição e integração entre elas. Encontramos aspectos que surgiram em fases "mais antigas" que são fundamentais na última fase e também muitas das tecnologias que surgiram essas fases continuam a ser utilizadas.

Tangram - Revista de Educação Matemática, Dourados - MS - v.1 n. 1, pp. 54 - 74 (2018) 
Com isso, reproduzimos um diagrama (Figura 4), apresentado por Borba, Silva e Gadanidis (2014), com o objetivo apresentar a concepção das relações entre as fases:

Figura 4: Diagrama de relação entre as fases

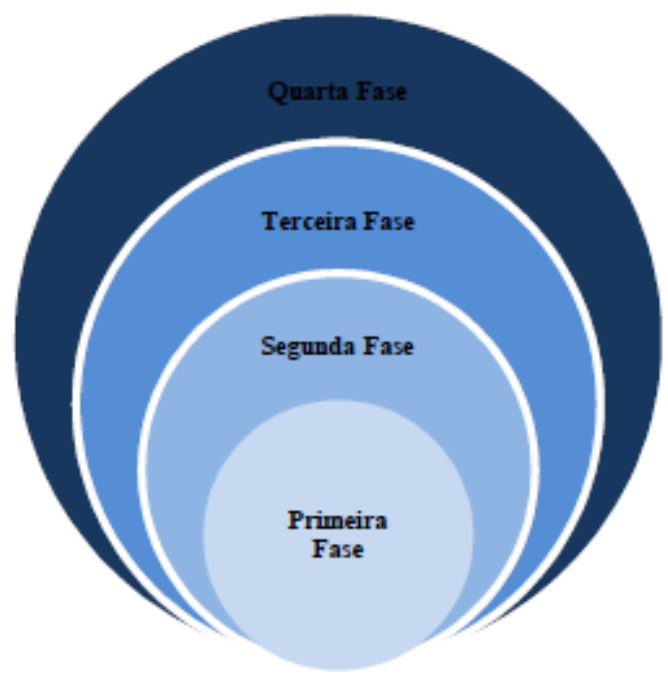

Fonte: Borba; Silva; Gadanidis, 2014, p.38

Ainda sobre o uso da tecnologia, Canavarro (1994, apud Carneiro, 2014) apresenta quatro formas de utilização dos computadores por professores de Matemática, que são:

(1) Elemento de motivação para aumentar o interesse dos alunos pelas aulas, (2) Elemento de modernização, por fazer parte dos diversos âmbitos da sociedade, (3) Elemento de facilitação para realizar tarefas que podem ser feitas manualmente, como cálculos e construção de gráficos, (4) Elemento de mudança para criar novas dinâmicas educativas, ou seja, para realizar tarefas que seriam difíceis de fazer sem o computador, provocando inovações no processo de ensino e aprendizagem. (p. 105).

Frente a tantas possibilidades para o uso de tecnologia nas aulas de Matemática, resolvemos pesquisar, com professores de Matemática da cidade de Dourados, como estava o uso dessas e de outras tecnologias nas aulas de Matemática, passaremos a detalhar nossa pesquisa.

\section{5- Metodologia}

Pudemos constatar, ao longo de nossa pesquisa bibliográfica, que a tecnologia está presente em nosso cotidiano, nas escolas, nas salas de aula e também nas aulas de Tangram - Revista de Educação Matemática, Dourados - MS - v.1 n. 1, pp. 54 - 74 (2018) 
Matemática, dessa forma, com o objetivo de saber se os professores de Matemática da cidade de Dourados (MS), utilizam tecnologias em suas aulas, buscou-se neste trabalho, responder a seguinte questão: Os professores de Matemática da cidade de Dourados, estado de Mato Grosso do Sul, utilizam tecnologias em suas aulas?

Nesse contexto objetivou-se também saber um pouco sobre a relação dos professores com as tecnologias, as mais utilizadas nas aulas, bem como sua frequência e os softwares conhecidos e usados. Quando mencionamos tecnologia na pesquisa aplicada, estamos nos referindo ao uso de computadores tablets e softwares, celular, câmera digital, GPS (Global Positioning System), reprodutores de música e calculadoras (tecnologias que fizeram parte de nosso questionário).

Portanto, de acordo com nosso foco central, a utilização das tecnologias nas aulas de Matemática por professores de Matemática da cidade de Dourados, Mato Grosso do Sul, visando responder a questão de investigação apresentada, escolhemos realizar um estudo do tipo "levantamento" ou "survey", que de acordo com Fiorentini e Lorenzato (2006), "é um tipo de estudo exploratório que procura abranger um grande número de sujeitos, mediante aplicação de questionários" (p. 106). Os autores também explicitam que "tal qual uma foto, esse método de pesquisa fornece uma visão estática e momentânea” (p. 106), complementando que "ela mostra-se útil quando se deseja obter uma visão geral de uma situação ou problema" (p. 106).

Nesse sentido, foi elaborado um questionário, previamente validado, com um grupo menor de participantes. O questionário foi enviado para 12 professores via e-mail contendo um link para a ferramenta chamada "googleforms" (disponibilizado entre os meses de Dezembro de 2015 e Março de 2016), dos quais quatro responderam.

Em complemento, o mesmo questionário foi entregue, de forma impressa a 35 professores, como meta de alcançar um número maior de professores. Desses 35 questionários entregues, recebemos retorno de 25, totalizando assim os 29 professores participantes dessa pesquisa. A base de e-mails foi composta por e-mails do arquivo pessoal do pesquisador e por outros disponibilizados por colegas de curso e professores. O contato para entrega dos questionários impressos se deu via escolas parceiras que recebiam estudantes para a realização do estágio obrigatório.

Tangram - Revista de Educação Matemática, Dourados - MS - v.1 n. 1, pp. 54 - 74 (2018) 
O questionário, de acordo com Fiorentini e Lorenzato (2006) é considerado como um instrumento tradicional de coleta de informações. Consistia numa série de 16 perguntas. As questões foram classificadas como fechadas e mistas.

Tendo em vista essa clarificação passaremos agora para a análise e interpretação dos dados obtidos nessa pesquisa, que representa uma parcela dos professores da cidade de Dourados. Devido a natureza da pesquisa (Iniciação Científica), ao tempo de desenvolvimento da mesma, não foi possível enviar questionário a todos os professores da cidade.

\section{6- Análise e interpretação dos dados}

Esta pesquisa foi realizada com 29 professores de escolas públicas da cidade de Dourados, Mato Grosso do Sul, considerando dois tipos de participação, o preenchimento de formulário impresso e por meio de formulário eletrônico. Destes participantes 21 são mulheres e 8 são homens, distribuídos conforme a faixa etária variando de 21 até 46 anos ou mais (Tabela 1).

Tabela 1: Faixa etária dos participantes da pesquisa

\begin{tabular}{cc}
\hline Faixa-etária & Quantidade \\
\hline 21 a 25 anos & 04 \\
26 a 30 anos & 06 \\
31 a 35 anos & 07 \\
36 a 40 anos & 03 \\
41 a 45 anos & 06 \\
46 anos ou mais & 03 \\
Total & $\mathbf{2 9}$ \\
\hline \multicolumn{2}{c}{}
\end{tabular}

Embora com participantes em todas as faixas etárias, um número maior de professores na faixa entre 31 e 35 anos e de acordo com o exposto por Borba, Silva e Gadanidis (2014), estes professores percorreram as quatro fases das tecnologias digitais em Educação Matemática citadas anteriormente. Quanto à formação dos participantes temos certo equilíbrio entre graduação e especialização, não sendo citados as demais formações como mestrado, doutorado ou pós-doutorado. Também se notou um equilíbrio entre a atuação nas séries finais do Ensino Fundamental e no Ensino Médio, sendo que alguns atuam em ambos os níveis de ensino.

Tangram - Revista de Educação Matemática, Dourados - MS - v.1 n. 1, pp. 54 - 74 (2018) 
$\mathrm{Na}$ questão que refere se ao primeiro acesso à um computador, nenhum participante obteve-o anteriormente à 1986, 1 entre 1986 e 1990, 2 entre 1991 e 1995, 21 participantes, obtiveram-no entre 1996 e 2005 aproximadamente o que segundo Borba, Silva e Gadanidis (2014) aponta em suas classificações, como incluídos na segunda fase (popularização dos computadores), terceira e quarta fase, a mais atual, 4 entre 2006 e 2010 e 1 após 2010 o que também está intimamente ligado a dispositivos utilizados no cotidiano (Tabela 2).

Tabela 2: Dispositivos utilizados no cotidiano dos participantes.

\begin{tabular}{cc}
\hline Dispositivos & Quantidade \\
\hline Computador & 25 \\
Tablet & 03 \\
Celular & 29 \\
Câmera Digital & 02 \\
Mapas/ GPS & 01 \\
Calculadoras & 04 \\
Outros & 21 \\
Reprodutores de Música (MP3/MP4) & - \\
\hline \multicolumn{2}{c}{ Fonte: Elaborado pelos autores. }
\end{tabular}

Expressivamente 25 participantes utilizam computador e 29 (todos) utilizam celular em seu cotidiano o que pode indicar uma tendência atual com o avanço das diversas funções e importância que esses dispositivos têm tomado na sociedade atualmente, sem deixar de notar também que 21 participantes utilizam calculadoras.

Conforme exposto acima, na sequência foi feita uma pergunta em relação à frequência da utilização de tecnologias no cotidiano, e obtivemos como resposta que a maioria dos participantes utilizam de 3 a 6 vezes por dia.

Cada vez mais a informação tem se disseminado por diversos meios e em altíssima velocidade, relevando a importância de manter se atualizado atualmente, dessa forma questionou-se aos participantes se leem notícias, dos quais 28 participantes leem, e quais assuntos costumam ler (Tabela 3).

Tabela3: Assuntos lidos pelos participantes em noticiários.

\begin{tabular}{cc}
\hline Assuntos & Quantidade \\
\hline Não leio noticias & 01 \\
Tecnologia & 11 \\
Ciências & 10 \\
Educação & 12 \\
Esporte & 12 \\
Economia & 17 \\
Culinária & 10 \\
Outro & 03 \\
\hline
\end{tabular}

Fonte: Elaborado pelos autores.

Tangram - Revista de Educação Matemática, Dourados - MS - v.1 n. 1, pp. 54 - 74 (2018) 
Após as perguntas de perfil, formação e interesses, seguimos para perguntas sobre a utilização de tecnologias em sala de aula, a frequência de utilização (Tabela 4) e qual(is) tecnologias (Tabela 5), o que pode mostrar ou não reflexo de como ela é utilizada no cotidiano e sua familiaridade com tal tecnologia. A seguir as tabelas 4 e 5:

Tabela4: Frequência de utilização de tecnologias em sala de aula

\begin{tabular}{cc}
\hline Frequência & Quantidade \\
\hline Não utilizo & 02 \\
1 vez por bimestre & 18 \\
1 vez por mês & 08 \\
Quinzenalmente & 01 \\
1 vez por semana & - \\
2 vezes por semana ou mais & - \\
\hline
\end{tabular}

Fonte: Elaborado pelos autores.

Tabela 5: Tecnologias utilizadas em sala de aula

\begin{tabular}{cc}
\hline Tecnologias & Quantidade \\
\hline Internet & 15 \\
Projetor/Data Show & 20 \\
Computador & 25 \\
Blog & - \\
Lousa Digital & 01 \\
Outro & - \\
\hline & Fonte: Elaborado pelos autores.
\end{tabular}

Assim tivemos que 27 participantes utilizam tecnologias em sala de aula e desses, 18 utilizam ao menos uma vez no bimestre, o que mostra uma boa iniciativa por parte dos professores em trazer novos elementos didáticos à sala de aula, desprendendo-se um pouco do tradicional quadro e giz, que por muitas vezes monotoniza a aula, entretanto pode se questionar: Se o professor utiliza tecnologias variadas diariamente em sua maioria, porque utilizá-la apenas uma vez por bimestre em suas aulas e não mais?

Borba, Silva e Gadanidis (2014) apontam na segunda fase a importância que alguns softwares voltados à geometria dinâmica e representatividade de funções tiveram na história da utilização de tecnologias digitais em Educação Matemática e então com base nisso perguntou-se sobre o conhecimento de algum software de Matemática (Tabela 6) e de que forma conheceu (se conheceu algum) tal (is) software (s) logo mais abaixo na Tabela 7.

Tabela 6: Softwares de Matemática conhecidos pelos professores

Tangram - Revista de Educação Matemática, Dourados - MS - v.1 n. 1, pp. 54 - 74 (2018) 


\begin{tabular}{cc}
\hline Software & Quantidade \\
\hline GeoGebra & 27 \\
ClicMat & 06 \\
LOGO & 14 \\
Máxima & 01 \\
GraphEquation & 04 \\
Winplot & 12 \\
Cabri Geomètre & 02 \\
Outro & - \\
\hline \multicolumn{2}{c}{}
\end{tabular}

Tabela 7: Forma de conhecimento do software

\begin{tabular}{cc}
\hline Forma & Quantidade \\
\hline Não conheço nenhum & 01 \\
Durante a graduação ou mestrado & 24 \\
Durante palestras, oficinas, eventos, simpósios, entre outros. & 06 \\
Algum colega apresentou-lhe & 04 \\
Algum aluno apresentou-lhe & - \\
\hline Fonte: Elaborado pelos autores.
\end{tabular}

Conforme podemos verificar na Tabela 6 e relacionando com o proposto por Borba, Silva e Gadanidis (2014) os softwares mais conhecidos são os que estes autores propõem ao classificar fases na história da utilização de tecnologias digitais em Educação Matemática, que são: LOGO, Winplot, CabriGeomètre e Geogebra.

Ainda Borba, Silva e Gadanidis (2014) apontam na primeira fase a contribuição da utilização de calculadoras simples e científicas e dessa forma por fim perguntou se os professores utilizam ou já utilizaram calculadoras em sala de aula. Há 28 participantes que afirmaram sua utilização.

Os Parâmetros Curriculares Nacionais (1998), colocam que a calculadora tem se tornado parte significativa da população o que podemos verificar nos dias atuais e conforme 28 participantes expressivamente afirmaram sua utilização, é um instrumento que pode contribuir para a melhoria do ensino da Matemática, podendo ser utilizada como um instrumento motivador na realização de tarefas exploratórias e de investigação, sendo também um recurso para verificação de resultados, correção de erros, entre outros podendo ser um instrumento de auto - avaliação, levando a percepção da importância do uso de meios tecnológicos disponíveis na sociedade. Em razão a limitação dessa pesquisa não foi possível investigar mais detalhadamente a (s) qual (is) tarefas eram / são utilizadas as calculadoras pelos participantes.

Durante contato com a sala de aula, estágio supervisionado e as leituras teóricas é possível notar indícios de que muitos professores vêm procurando dinamizar a forma como Tangram - Revista de Educação Matemática, Dourados - MS - v.1 n. 1, pp. 54 - 74 (2018) 
ensinam Matemática e inserir tecnologias em sua aula e trazer o aluno já inserido na era da tecnologia da informação e comunicação cada vez mais para si e sua aula contribuindo fortemente para o aprendizado matemático do aluno e também quebrando a monotonia de uma aula sempre utilizando quadro e giz. Carneiro e Passos (2014) trazem que:

Esse movimento de sair da zona de conforto para caminhar pela zona de risco não é um processo fácil e demanda apoio e segurança para enfrentar os desafios que essa prática impõe e que pode ser conseguida com a formação contínua, a participação em grupos de estudos, etc (p. 117).

Esse novo contexto da tecnologia permeando os processos educativos, traz ao professor novos desafios. O coloca como também aprendiz de um processo que está em constante transformação, onde o conhecimento é construído e reconstruído colaborativamente, mudando assim a perspectiva de que o professor é o único detentor do conhecimento dentro da sala de aula. As tecnologias podem proporcionar um novo momento pedagógico onde o estudante torna-se ativo e protagonista de sua formação e o professor continua sendo fundamental na mediação desse processo. Tendo em vista o exposto, passaremos agora as considerações finais.

\section{7- Algumas considerações}

Embora a utilização de tecnologias digitais não signifiquem necessariamente a melhoria da qualidade no processo de ensino e aprendizagem em nossas escolas e que muitas vezes, a adesão e a incorporação de tecnologias possam camuflar práticas convencionais, ou ter apenas como argumento de sua inserção, a preparação para o mercado de trabalho, a tecnologia e principalmente a internet já trazem contribuições ao conhecimento dos alunos hoje em dia. De fato podemos dizer que o acesso à tecnologia não é igual, nem tampouco frequente a todos, entretanto é possível verificar cada vez mais a importância que esta assume, seja na própria sala de aula ou nos "bastidores" na formação desses professores, por exemplo, e também na importância do professor no seu bom uso.

Ao questionar-nos: Se o professor utiliza tecnologias variadas diariamente em sua maioria, porque utilizá-la apenas uma vez por bimestre em suas aulas e não mais?, pudemos verificar que professores de Matemática da cidade Dourados, Mato Grosso do Sul, que participaram da pesquisa, embora apontaram utilizar tecnologias em seu cotidiano em maior frequência (diariamente) do que em sala de aula (bimestralmente), e ainda sim, o resultado

Tangram - Revista de Educação Matemática, Dourados - MS - v.1 n. 1, pp. 54 - 74 (2018) 
mostrado é tímido frente a realidade que almejamos encontrar, ou seja, uma sala de aula e um ensino de Matemática mais motivador e mais conectado com a realidade. Tal aspecto pode ser considerado, como um indicativo de que estes professores em um futuro não muito distante possam agregar mais uso de tecnologias e aumentar sua frequência de utilização.

Frente a tantas contribuições e possibilidades quanto a utilização de tecnologias em sala de aula (em especial, nas aulas de matemática), podemos esperar que a cada novo instante, novas tecnologias irão fazer parte da rotina dos estudantes e professores, uma vez que atualmente tem se tornado uma forte tendência tal utilização, principalmente em relação aos portáteis como o smartphones e tablets, por exemplo e que nesse contexto, computador, por exemplo, pode se tornar uma tecnologia tradicional. Ainda nessa mesma linha é possível que o relacionamento dos professores com as tecnologias seja mais interligada por meio de descobertas juntamente aos estudantes e assim tenhamos mais professores abertos a trafegarem em zonas de risco.

Finalizamos aqui acreditando que futuramente possamos dar novos caminhos a esse trabalho, selecionando alguns professores conhecendo e estudando mais profundamente a utilização de tecnologias na sala de aula no campo de vista também dos próprios alunos, bem como se possível até propondo algumas intervenções de situações problema para serem aplicados com uso de tecnologias e em maior frequência à utilizada pela grande maioria dos professores.

\section{Referências Bibliográficas}

Bittar, M. (2010) A escolha do software educacional e a proposta didática do professor: estudo de alguns exemplos em Matemática. In: BELINE, W.; COSTA, N. M. L. Educação Matemática, Tecnologia e Formação de Professores: algumas reflexões. Editora da FECILCAM. Campo Mourão.( 272 p.)

Borba, M. C.; Silva, R. S. R.; Gadanidis, G. (2014) Fases das tecnologias digitais em Educação Matemática: Sala de aula e internet em movimento. 1 ed. Belo Horizonte. Autentica .

Carneiro, R. F. (2008) Da licenciatura ao início da docência: vivências de professores de matemática na utilização das tecnologias da informação e comunicação. Dissertação (Mestrado) -- Universidade Federal de São Carlos: UFSCar, $171 \mathrm{f}$.

Tangram - Revista de Educação Matemática, Dourados - MS - v.1 n. 1, pp. 54 - 74 (2018) 
Carneiro, R. F., Passos, C. L. B. (2014) A utilização das Tecnologias de Informação e Comunicação nas aulas de Matemática: Limites e possibilidades. Revista Eletrônica de Educação, (v.8, n. 2, p. 101-119) Disponível em http://dx.doi.org/10.14244/19827199729.

Filho, J. A. C., Maia, D. L., Castro, J. B., Barreto, A. L. O., Freire, R. S. (2016) Das Tabuletas aos Tablets: tecnologias e aprendizagem da Matemática. In: FILHO, J. A. C., BARRETO, M. C., BARGUIL, P. M., MAIA, D. L., PINHEIRO, J. L. Matemática, Cultura e Tecnologia: perspectivas internacionais. Curitiba. CRV.

Fiorentini, D.; Lorenzato, S. (2006) Investigação em educação matemática: Percursos teóricos e metodológicos. $1^{\mathrm{a}}$ Ed. Campinas - SP.

Kenski, V. M. (2003) Aprendizagem mediada pela tecnologia. Revista Diálogo Educacional, Curitiba, (v. 4, n.10, p.47-56, set./dez).

Miranda, G. L.(2007) Limites e possibilidades das TIC na educação. SÍSIFO / Revista de Ciências da Educação. (nº 3. Mai/Ago. pp. 41-50)

Paz, R. O. (2014) Construção de gráficos utilizando o software planilha eletrônica. Dissertação (Mestrado Profissional em Matemática) - Universidade Federal da Grande Dourados (UFGD). Dourados. $53 \mathrm{f}$.

Silva, D. R. (2017) O Uso de Tecnologias nas Aulas de Matemática na Cidade de Dourados - Mato Grosso Do Sul. 46 p. Trabalho de conclusão de curso (Licenciatura em Matemática). Faculdade de Ciências Exatas e Tecnologia. Universidade Federal da Grande Dourados, Dourados.

Tangram - Revista de Educação Matemática, Dourados - MS - v.1 n. 1, pp. 54 - 74 (2018) 
Uso de Tecnologias nas Aulas de Matemática: Pesquisa com Professores da Cidade de Dourados (MS)

Recebido: 08/01/2018

Aceito: 22/02/2018

Tangram - Revista de Educação Matemática, Dourados - MS - v.1 n. 1, pp. 54 - 74 (2018) 